\title{
Pengaruh Servicescape, Kualitas Layanan, dan Persepsi Harga Terhadap Kepuasan Konsumen pada Larissa Aesthetic Center Cabang Purwokerto
}

\author{
Ady Achadi*, Intan Nur Septiani, Tri Esti Masita \\ Fakultas Ekonomika dan Bisnis \\ Universitas Wijayakusuma Purwokerto, Banyumas \\ *correspondence email: adyachadi@unwiku.ac.id
}

\begin{abstract}
The purpose of this study was to analyze the effect of servicescape, service quality and price perception on consumer satisfaction at Larissa Aesthetic Center Purwokerto. The research population is the consumers of Larissa Aesthetic Center Purwokerto, with a sample of 104 respondents. The sampling technique used was accidental sampling. Research method using multiple linear regression. The results of the study show that servicescape and service quality have a positive and significant effect on consumer satisfaction at Larissa Aesthetic Center Purwokerto. Price perception has not significant effect on consumer satisfaction at Larissa Aesthetic Center Purwokerto. This finding implies the need to maintain and improve the concept of the existing servicescape by adding instructions to the room to make it easier for consumers to understand the function of the room at the Larrissa Aesthetic Center Purwokerto. In addition, providing security guarantees and the risk of damage as well as paying attention to the neatness of the appearance of employees in order to add positive value to the company.
\end{abstract}

Keywords: Servicescape, Service Quality, Price Perception, Consumer Satisfaction.

\section{Pendahuluan}

Saat ini penampilan yang baik sudah dianggap sebagai suatu kebutuhan, tidak hanya bagi kalangan wanita tetapi juga laki-laki, sehingga bisnis di sektor perawatan tubuh menjadi berkembang tidak hanya di kota besar tetapi juga sampai pada kota kabupaten. Dengan berkembangnya sektor bisnis tersebut tentunya menimbulkan tingkat persaingan yang semakin besar, dan untuk memenangkan persaingan salah satunya caranya adalah dengan memberikan kepuasan kepada konsumen. Kotler \& Keller (2009) mengemukakan bahwa kepuasan konsumen ialah perasaan bahagia ataupun kecewa seorang yang timbul setelah membandingkan kinerja ataupun hasil produk yang dipikirkan terhadap kinerja yang diharapkan. Saat ini di Purwokerto terdapat banyak klinik perawatan tubuh tetapi mereka hanya mentargetkan pada konsumen wanita saja, dan salah satu klinik perawatan tubuh yang menawarkan pelayanan perawatan kulit, rambut serta badan baik untuk wanita maupun laki-laki adalah Larissa Aesthetic Center yang mempunyai banyak cabang, tidak hanya di Purokerto tetapi juga di Semarang, Yogyakarta, Magelang, Klaten, Solo, Kudus, Salatiga, Tembalang, Sragen, Tegal, Jember, Malang, Mojokerto, Ponorogo, Surabaya, Tenggilis, Denpasar, Kediri, Madiun, Pekalongan, dan Cilacap. Dengan demikian penelitian ini memilih Larrissa Aesthetic Center cabang Purwokerto sebagai obyek penelitian. Dalam mewujudkan kepuasan konsumen di Larrissa Aesthetic Center cabang Purwokerto peneliti menduga bahwa kepuasan konsumen dipengaruhi oleh servicescape, kualitas layanan, dan persepsi harga.

Servicescape ialah salah satu aspek yang dapat mempengaruhi kepuasan komsumen (Sahanggamu, et al., 2015). Studi empiris Masloman, et al (2014) dan Dewi (2019) menemukan bahwa servicescape memiliki pengaruh positif dan signifikan terhadap kepuasan konsumen. Tetapi Fahleti (2018) menemukan bahwa servicescape berpengaruh negatif dan tidak signifikan terhadap kepuasan konsumen. Servicescape yang ada dalam suatu layanan jasa dapat mempengaruhi persepsi konsumen atas kualitas yang dirasakan konsumen dan kemudian dapat meningkatkan kepuasan. Menurut Lupiyoadi, (2013) servicescape adalah lingkungan fisik yang terdapat pada perusahaan jasa ketika konsumen berinteraksi serta dengan adanya unsur berwujud yang berguna untuk menggambarkan atau mendukung peranan pada jasa tersebut. Konsep dari servicescape yang dipersepsikan nyaman oleh konsumen, pada dasarnya dapat memberikan pengaruh yang baik bagi pikiran serta perasaan konsumen yang kemudian akan menciptakan kepuasan atas lingkungan fisik yang nyaman ditempat layanan jasa Faktor lain yang diduga memengaruhi kepuasan konsumen adalah kualitas layanan (Kartikasari, et al, 2014). Studi Nurmalasari (2013), Haryanto (2013), Dennisa \& Santoso (2016) dan Dewi (2019) menemukan bahwa kualitas layanan berpengaruh positif dan signifikan terhadap kepuasan pelanggan. Hal berbeda diperoleh Lauw (2013) yang menemukan bahwa kualitas layanan berpengaruh negatif terhadap kepuasan pelanggan. Menurut Kotler \& Keller (2009) produk, kualitas layanan, kepuasan konsumen dan profitabilitas perusahaan memiliki hubungan yang sangat erat. Selanjutnya Menurut Parasuraman, et al (1988) kualitas layanan merupakan anggapan ataupun penilaian konsumen terhadap pelayanan yang mereka terima pada saat tertentu. Kualitas layanan dan kepuasan konsumen mimliki hubungan yang sangat erat. Semakin baik kualitas layanan yang diberikan oleh suatu perusahaan, maka semakin baik pula tingkat kepuasan yang 
dirasakan oleh konsumen. Hal ini menyatakan bahwa semakin tinggi kualitas layanan yang diberikan oleh suatu perusahaan, maka semakin tinggi pula tingkat kepuasan yang dirasakan oleh konsumen, begitu pula sebalikya.

Selain itu persepsi harga diduga dapat mempengaruhi kepuasan konsumen (Zakaria \& Suwitho, 2017). Studi (Montung, 2015) menemukan bahwa persepsi harga mempunyai pengaruh yang positif dan signifikan terhadap kepuasan pelanggan. Tetapi studi empiris (Wariki, et al, 2015) menemukan bahwa persepsi harga berpengaruh negatif terhadap kepuasan konsumen. Menurut Schiffman \& Kanuk, (2007) persepsi harga merupakan persepsi konsumen tentang suatu harga dan bagaimana konsumen tersebut melihat harga suatu produk dan jasa bisa tinggi, rendah, maupun wajar yang dapat memberikan pengaruh yang cukup kuat terhadap kepuasan setelah konsumen melakukan pembelian. Menurut Liu \& Arnet, (2000) persepsi harga memberikan peran yang cukup penting dalam mempengaruhi kepuasan konsumen setelah melakukan pembelian. Selain itu, Lee, et al (2011), mengatakan bahwa persepsi harga ialah pemberian nilai yang diberikan konsumen serta bentuk emosional mengenai suatu harga apakah harga yang diberikan oleh suatu perusahaan dan harga yang konsumen bandingkan dengan perusahaan lain masuk akal, dan dapat diterima atau tidak. Persepsi harga memiliki peranan yang sangat penting dalam mencapai tingkat kepuasan konsumen. Tujuan penelitian ini adalah untuk membuktikan apakah servicescape, kualitas layanan, dan persepsi harga berpengaruh terhadap kepuasan konsumen di Larrissa Aesthetic Center cabang Purwokerto.

\section{Metode}

Jenis penelitian ini adalah penelitian kuantitatif. Menurut Sugiyono (2017) penelitian kuantitatif dapat dikatakan sebagai suatu cara penelitian untuk meneliti suatu populasi maupun sampel tertentu dengan cara mengumpulkan data melalui instrumen penelitian. Menurut Nawawi (1983) populasi merupakan semua objek penelitian seperti manusia, tumbuhan, hewan, benda, pengalaman, maupun nilai tes yang dijadikan sumber data dan memiliki karakteristik khusus pada suatu penelitian yang akan dilakukan. Karena dalam penelitian ini jumlah populasi yang merupakan konsumen Larrissa Aesthetic Center cabang Purwokerto tidak terdata, maka untuk menentukan besarnya sampel digunakan rumusan yang dikemukakan oleh Sekaran (2006) sehingga ditemukan sebanyak 104 responden dengan menggunakan teknik accidental sampling. Selanjutnya untuk melakukan pengujian signifikansi pengaruh variabel servicescape, kualitas layanan dan persepsi harga terhadap kepuasan konsumen dalam penelitian ini dilakukan menggunakan analisis regresi linier berganda. Teknik analisis data dalam penelitian ini menggunakan metode regresi linear berganda. Berikut ini model penelitian : $Y=a+b_{1} X_{1}+b_{2} X_{2}+b_{3} X_{3}+e$

Keterangan: $\mathrm{Y}=$ kepuasan konsumen; $\mathrm{a}=$ konstanta; $\mathrm{b}_{1}, \mathrm{~b}_{2}, \mathrm{~b}_{3}=$ koefisien regresi; $\mathrm{X}_{1}=$ servicescapeI; $\mathrm{X}_{2}=$ kualitas layanan; $\mathrm{X}_{3}=$ persepsi harga; $\mathrm{e}=$ standar error

Selanjutnya untuk mendapatkan hasil regresi yang tidak bias dilakukan uji asumsi klasik yang digunakan adalah uji normalitas yaitu untuk menguji apakah variabel dependent dan variabel indpendent berdistribusi normal atau tidak, multikolineritas yaitu untuk mengetahui apakah model regresi ditemukan adanya korelasi antar variabel independent atau variable bebas, dan heteroskedastisitas yaitu untuk mengethaui apakah model regresi terjadi perbeedaan variance dari residual satu pengamatan ke pengamatan yang lain (Ghozali, 2016).

\section{Hasil}

Tabel 1

Analisis Regresi Linear Berganda

\begin{tabular}{r|r|r}
\hline \multicolumn{1}{c|}{ Variabel } & koefisien & Probabilitas \\
\hline Servicescape & 0,452 & 0,000 \\
\hline Kualitas Layanan & 0,474 & 0,000 \\
\hline Persepsi Harga & $-0,158$ & 0,062 \\
\hline Konstanta $=4,188$ & & \\
R Square $=0,501$ & & \\
F hitung $=33,50$ & & \\
\hline
\end{tabular}

Sumber : data olahan

Nilai koefisien servicescape bertanda positif dan nilai probabilitas sebesar 0,000 lebih kecil dari alpha yaitu 0,05. Oleh karena itu, dapat disimpulkan bahwa servicescape berpengaruh positif signifikan terhadap kepuasan konsumen di Larrissa Aesthetic Center cabang Purwokerto. Pengaruh tersebut menunjukkan bukti bahwa semakin baik servicescape, maka akan semakin besar kepuasan konsumen di Larrissa Aesthetic Center cabang Purwokerto. Secara teoritis, temuan ini sejalan dengan Sahanggamu et al. (2015) yang menyatakan bahwa Servicescape ialah salah satu aspek yang dapat mempengaruhi kepuasan komsumen. Secara empiris, temuan ini mendukung penelitian Masloman, et al (2014) dan Dewi (2019) yang menyatakan bahwa servicescape memiliki pengaruh positif dan signifikan terhadap kepuasan konsumen. Penelitian ini menemukan bahwa penilaian konsumen terhadap servicescape 
yang terdapat pada Larissa Aesthetic Center cabang Purwokerto menimbulkan kepuasan bagi konsumen ketika konsumen melakukan perawatan. Servicescape memiliki peranan yang cukup penting sebagai pembentuk pengalaman konsumen. Kenyamanan pada desain interior yang dirasakan konsumen pada saat melakukan perawatan. Lahan parkir yang terdapat di Larissa cukup luas, sehingga mempermudah konsumen saat keluar dan masuk Larissa. Kondisi di ruang tunggu di Larissa dirasa nyaman oleh konsumen karena menyediakan tempat duduk yang cukup. Tanda -tanda dan symbol yang ada di Larissa dapat dipahami dengan jelas oleh konsumen untuk membantu konsumen dalam menemukan apa yang dicari. Maka dengan adanya servicescape yang nyaman di Larissa Aesthetic Center cabang Purwokerto dapat menimbulkan kepuasan bagi para konsumen. Dengan adanya tanda tanda tersebut, konsumen merasa lebih mudah dalam menjumpai toilet, ruang konsultasi, ruang tunggu, ruang perawatan dan lain sebagaiya. Servicescape dan kepuasan konsumen memiliki hubungan yang sangat erat. Apabila konsumen merasa nyaman saat melakukan perawatan karena konsep dari servicescape itu sendiri, maka konsumen akan cenderung merasa puas dan tercipta kepuasan konsumen atas suasana yang dapat dikatakan nyaman pada lingkungan sekitar.

Nilai koefisien kualitas layanan bertanda positif dan nilai probabilitas sebesar 0,000 lebih kecil dari alpha yaitu 0,05. Oleh karena itu, dapat disimpulkan bahwa kualitas layanan berpengaruh positif signifikan terhadap kepuasan konsumen di Larrissa Aesthetic Center cabang Purwokerto. Pengaruh tersebut menunjukkan bukti bahwa semakin baik kualitas layanan, maka akan semakin besar kepuasan konsumen di Larrissa Aesthetic Center cabang Purwokerto. Secara teoritis, temuan ini sejalan dengan Kartikasari, et al (2014) yang menyatakan bahwa kualitas layanan mempengaruhi kepuasan komsumen. Secara empiris, temuan ini mendukung penelitian Nurmalasari (2013), Haryanto (2013), Dennisa \& Santoso (2016) dan Dewi (2019) yang menyatakan bahwa kualitas layanan memiliki pengaruh positif dan signifikan terhadap kepuasan konsumen. Penelitian ini menemukan bahwa penilaian konsumen terhadap layanan yang diberikan oleh Larissa Aesthetic Center cabang Purwokerto telah sesuai dengan yang dijanjikan seperti memberikan pelayanan yang cepat kepada konsumen, kemampuan karyawan baik dalam bidang kecantikan yang diberikan, dan penampilan yang rapih dari karyawan Larissa Aesthetic Center cabang Purwokerto. Hal tersebut dapat memberikan pengaruh yang baik dalam menciptakan kepuasan konsumen. Hasil tersebut sejalan dengan teori yang dikemukakan Parasuraman, et al (1988) bahwa kualitas layanan memengaruhi kepuasan konsumen. Semakin baik kualitas layanan yang diberikan oleh suatu perusahaan, maka semakin baik pula tingkat kepuasan yang dirasakan oleh konsumen.

Nilai koefisien persepsi harga bertanda negatif dan nilai probabilitas sebesar 0,062 lebih besar dari 0,05. Oleh karena itu, dapat disimpulkan bahwa persepsi harga tidak berpengaruh signifikan terhadap kepuasan konsumen di Larrissa Aesthetic Center cabang Purwokerto. Secara teoritis, temuan ini tidak sejalan dengan Zakaria \& Suwitho (2017) yang menyatakan bahwa persepsi harga mempengaruhi kepuasan komsumen. Secara empiris, temuan ini mendukung penelitian Wariki et al (2015) dan Rizan, et al (2015) yang menyatakan bahwa persepsi harga tidak berpengaruh signifikan terhadap kepuasan konsumen. Tetapi bertolak belakang dengan temuan Montung (2015) yang menyatakan bahwa persepsi harga mempunyai pengaruh yang positif dan signifikan terhadap kepuasan pelanggan. Penelitian ini menemukan bahwa persepsi konsumen terhadap harga yang ditetapkan oleh Larissa Aesthetic Center cabang Purwokerto tidak cukup terjangkau dan cenderung lebih mahal dibanding dengan harga yang ditetapkan oleh klinik kencantikan yang lain tetapi konsumen menilai adanya kesesuaian antara harga dengan kualitas dan manfaat yang diterima. Ini berarti konsumen yang telah merasa puas, tidak mempertimbangkan harga, karena konsumen Larissa Aesthetic Center cabang Purwokerto merupakan kalangan masyarakat ekonomi menengah ke atas, sehingga konsumen tidak terlalu mempertimbangkan harga.

\section{Simpulan}

Berdasarkan hasil penelitian dapat diambil kesimpulan bahwa servicescape dan kualitas pelayanan berpengaruh positif dan signifikan terhadap kepuasan konsumen di Larrissa Aesthetic Center cabang Purwokerto. Sementara itu, persepsi harga tidak berpengaruh signifikan terhadap kepuasan konsumen di Larrissa Aesthetic Center cabang Purwokerto. Temuan ini mengimplikasikan kebijakan perlunya mempertahankan dan meningkatkan konsep dari sebuah servicescape yang telah ada dengan menambah pemberian petunjuk pada setiap ruangan agar mempermudah konsumen dalam memahami fungsi ruangan di Larrissa Aesthetic Center cabang Purwokerto. Selain itu, memberikan jaminan keamanan dan resiko kerusakan serta memperhatikan kerapihan penampilan karyawan agar menambah nilai positif bagi perusahaan.

\section{Daftar Pustaka}

Dennisa, E. A., \& Santoso, S. B. (2016). Analisis Pengaruh Kualitas Produk, Kualitas Layanan, dan Citra Merek terhadap Loyalitas Pelanggan melalui Kepuasan Pelanggan sebagai Variabel Intervening (Studi pada Klinik Kecantikan Cosmedic Semarang). Diponegoro Journal of Management, 5(3), 997-1009. Retrieved from https://ejournal3.undip.ac.id/index.php/djom/article/view/14686 
Ady Achadi et al., Pengaruh Servicescape, Kualitas Layanan, dan Persepsi Harga Terhadap Kepuasan Konsumen pada Larissa Aesthetic Center Cabang Purwokerto

Dewi, R., C., K. (2019). Pengaruh Kualitas Pelayanan Dan Serviscape Terhadap Kepuasan Konsumen Pada Loris Beauty Clinic Di Kabupaten Jombang. Jurnal Eksekutif, 16(2), 295-307.

Fahleti, W. H. (2019). Pengaruh Servicescape Dan Kualitas Layanan Terhadap Kepuasan Konsumen Pada Rumah Makan Tepian Pandan Di Tenggarong. Jurnal Ekonomi \&Amp; Manajemen Indonesia, 18(2).

Ghozali, I. (2016). Aplikasi Analisis Multivariete Dengan Program IBM SPSS 23. Edisi 8, Badan Penerbit Universitas Diponegoro, Semarang.

Haryanto, E. (2013). Kualitas Layanan, Fasilitas, dan Harga Pengauhnya Terhadap Kepuasan Pengguna Jasa Layanan Kantor Samsat Manado. Jurnal EMBA 1(3), 750-760.

Kartikasari, D., Dewanto, A., \& Rochman, F. (2014). Pengaruh Kualitas Layanan terhadap Kepuasan dan Kepercayaan di Rumah Sakit Bunda Kandangan Surabaya. Jurnal Aplikasi Manajemen, 12(3), pp. 454-463.

Kotler, P., \& Keller, K. L. (2009). Manajemen Pemasaran, Erlangga, Jakarta.

Lauw, J. (2013). Analisa Pengaruh Kualitas Layanan Terhadap Kepuasan Pelanggan Di The Light Cuo Cafe Surabaya Town Square Dan The Square Surabaya. Jurnal Strategi Pemasaran, 1(1).

Lee, S., Illia, A. \& Lawson-Body, A. (2011), "Perceived price fairness of dynamic pricing", Industrial Management \& Data Systems, Vol. 111 No. 4, pp. 531-550.

Liu, C. \& Arnett, K. (2000). Exploring the factors associated with Web site success in the context of electronic commerce. Information \& Management. 38. 23-33

Lupiyoadi, R. (2013). Manajemen Pemasaran Jasa Berbasis Kompetensi (Edisi 3). Jakarta: Salemba Empat.

Masloman, M., Lumanauw, B., \& Trang, I. (2014). Kualitas Pelayanan dan servicescape Pengaruhnya Terhadap Kepuasan Konsumen Pada Kentucky Fried Chicken Multimart Ranotana Manado. Jurnal EMBA, 2(4), 58960.

Montung, P. (2015). Pengaruh Kualitas Produk, Kualitas Layanan, Dan Persepsi Harga terhadap Kepuasan Pelanggan Di Restoran Kawan Baru. Jurnal Berkala Ilmiah Efisiensi, 15(5), 678-689

Nawawi, H. (1983). Metode Penelitian Deskriptif. Gajah Mada University Press. Yogyakarta.

Nurmalasari, M., R. (2013). Pengaruh Kualitas Layanan Terhadap Kepuasan Pelanggan Klinik Kecantikan Profira Di Surabaya. Jurnal Ilmiah Mahasiswa Universitas Surabaya, 2(1), 1-11

Parasuraman, A P., Zeithaml, V., \& Berry, L. (1988). Servqual: A multiple- Item Scale for measuring consumer perceptions of service quality. Journal of retailing. 64(1). 12- 37

Rizan, M., Yulianti, D., \& Rahmi, R. (2015). The Influence Of Price And Service Quality Of Brand Image And Its Impact On Customer Satisfaction Gojek (Students Study On A State University Of Jakarta). JRMSI - Jurnal Riset Manajemen Sains Indonesia, 6(2), 639-658.

Sahanggamu, S., Mananeke, L., \& Sepang, J. (2015). Analisis kualitas layanan, Servicescape dan kepercayaan terhadap kepuasan nasabah pada PT. Bank Sinarmas Bitung, Jurnal EMBA, 3(1), 1084-1095.

Sekaran, U., (2008). Metodologi Penelitiaan untuk Bisnis. Jakarta: Salemba.

Schiffman \& Kanuk, (2007). Perilaku Konsumen. Edisi Kedua. Jakarta : PT. Indeks Gramedia

Sugiyono, S. (2017). Metode Penelitian Bisnis: Pendekatan Kuantitatif, Kualitatif, Kombinasi dan R\&D. Bandung : Alfabeta, CV

Wariki, G., M., Mananeke, L., Tawas, H. (2015). Pengaruh Bauran Promosi Persepsi Harga Dan Lokasi Terhadap Keputusan Pembelian Dan Kepuasan Konsumen Pada Perumahan Taman Sari Metropolitan Manado. Jurnal EMBA, 3(2), 1073-1085.

Zakaria, D, G., \& Suwitho, S. (2017). Pengaruh Kualitas Pelayanan, Kualitas Produk Dan Harga Terhadap Kepuasan Pelanggan: Jurnal ilmu dan Riset Manajemen, 6(4), 1-18. 